Guilherme Maia Mulder VAN DE GRAAF ${ }^{1}$ Rodrigo Romero CORRÊA ${ }^{1}$ Luis Cláudio Lopes Correia da SILVA ${ }^{1}$

André Luis do Valle De ZOPPA $^{1}$

\section{Correspondência para:} André Luis do Valle De ZOPPA Av. Prof. Orlando Marques de Paiva, 87 Cidade Universitária-Butantã 05508-000 - São Paulo-SP e-mail:alzoppa@usp.br

\title{
Estudo anátomo-cirúrgico do cólon transverso do eqüino por acesso paralombar esquerdo
}

\author{
1 - Departamento de Cirurgia da Faculdade de Medicina Veterinária e Zootecnia da
} Universidade de São Paulo, São Paulo-SP

\section{Resumo}

O cólon transverso é um estreitamento do canal alimentar, sujeito a sofrer processos obstrutivos. A ampliação do conhecimento sobre essa estrutura e adjacentes é de grande importância cirúrgica. Neste estudo foram utilizados 10 cadáveres de eqüinos de diferentes raças, idades e sexos, divididos em dois grupos de cinco. No primeiro grupo foi realizada uma incisão no $16^{\circ}$ espaço intercostal esquerdo e posterior ressecção da $16^{\mathrm{a}}$ costela. No segundo grupo a incisão foi feita sobre a $17^{a}$ costela com a remoção da mesma. Todas as estruturas identificadas foram registradas em fichas individuais, assim como a extensão exteriorizada do cólon transverso. Em todas os animais o cólon transverso foi totalmente visualizado e parcialmente exteriorizado, sendo que houve melhor manipulação e exteriorização no segundo grupo, além da maior facilidade no emprego da técnica, com a incisão sobre a costela a ser ressecada. Dessa forma, concluímos que o cólon transverso pode ser acessado pela fossa paralombar esquerda, sendo que a remoção da $17^{\mathrm{a}}$ costela proporciona o melhor acesso para essa estrutura.

\section{Introdução}

A porção do aparelho digestivo, denominada intestino grosso, tem início na base do ceco e segue até a porção final, chamada reto. O intestino grosso é dividido em porções denominadas cólons, segundo sua posição anátomo-topográfica e diâmetro do seu lúmen, sendo cólon maior e suas divisões, cólon transverso e cólon menor. ${ }^{1}$

O cólon transverso é a porção constrita entre os cólons maior e menor. Começa aproximadamente pela porção dorsal da $17^{\mathrm{a}}$ e $18^{\mathrm{a}}$ vértebras torácicas, onde passa da direita para a esquerda, cranial à raiz do mesentério, estando em sua porção medial, ventral à aorta abdominal, e à veia cava caudal, e em sua porção esquerda, posicionando-se ventralmente ao rim esquerdo e baço. ${ }^{1,2,3}$

A posição do cólon transverso e a origem do cólon menor são fixas e este fato é de importância clínica em relação às obstruções, pois deve se levar em conta que essa estrutura une o cólon dorsal direito que pode atingir cinqüenta centímetros de diâmetro, ao cólon menor, com sete centímetros e meio a dez centímetros de diâmetro. ${ }^{1}$ A importância desta região tornase maior quando se considera a possibilidade de ingestão de corpos estranhos pelos eqüinos, como borracha, areia, pedaços de madeira, pedras e plástico, que tendem a formar massas fibrosas. ${ }^{4}$ Há ainda a formação de concreções intestinais denominadas enterólitos, que estão relacionadas com a ingestão excessiva de magnésio, e que constantemente causam obstruções parciais ou totais no cólon transverso na passagem para o cólon menor. ${ }^{5}$

As abordagens cirúrgicas do abdômen têm sido utilizadas com sucesso para tratamento de processos intestinais obstrutivos, sendo muitas vezes necessário realizar laparotomia e enterotomia. ${ }^{6}$ Porém, a dificuldade de acessar diretamente o cólon transverso em um procedimento cirúrgico, devido à sua posição topográfica e fixação 
à parede dorsal do abdômen, faz com que a correção de processos obstrutivos da porção final do cólon dorsal direito, cólon transverso e início de cólon menor, seja de grande dificuldade. ${ }^{6}$

A região da $16^{a}$ a $17^{a}$ costela, que corresponde à parede tóraco-lombar que reveste o cólon transverso, é constituída pelas estruturas a seguir. A pele, que é mais espessa nas regiões dorsais, se apresenta aderida ao músculo cutâneo do tronco, que recobre a maior parte da fossa paralombar ${ }^{3}$; a segunda, camada muscular da fossa paralombar, tem-se o músculo serrátil dorsal caudal, que recobre a superfície lateral das últimas sete ou oito costelas, e que tem suas fibras direcionadas no sentido crânio-ventral. A seguir, tem-se o músculo intercostal externo que ocupa todo o espaço intercostal desde o bordo dos músculos levantadores das costelas, até a extremidade esternal da costela, e que possui suas fibras perpendiculares às costelas. Internamente ao músculo intercostal externo, tem-se o músculo intercostal interno, separados por uma fina fáscia, e apesar de terem suas fibras orientadas no mesmo sentido, ou seja, perpendicular às costelas, o músculo intercostal interno ocupa todo o espaço intercostal, incluindo a parte intercondral. ${ }^{1}$ Ainda na região referida, tem-se o músculo oblíquo externo do abdômen, que consiste no mais extenso músculo do flanco, e que está situado em região mais ventral, tendo seus feixes musculares orientados no sentido caudo-ventral. ${ }^{1,3}$

A vascularização da região do flanco é feita principalmente pelas artérias intercostais, e a inervação é proveniente dos nervos torácicos e intercostais, ou ainda do nervo costo-abdominal e lombar, no caso do músculo oblíquo externo do abdômen. ${ }^{1}$

A síndrome cólica consiste em processo doloroso da cavidade abdominal e representa grande importância clínica e cirúrgica na medicina veterinária eqüina, sendo que é de ocorrência freqüente nessa espécie. Esses distúrbios podem ser causados por processos inflamatórios abdominais, como a peritonite, e ou dos órgãos contidos nessa cavidade, como processos inflamatórios intestinais (enterites e colites), doenças hepáticas, gástricas ou ainda renais. ${ }^{2}$ Entretanto, dependendo da causa da dor abdominal aguda, esta pode ser de indicação cirúrgica, como em processos obstrutivos, estrangulativos ou não, das alças intestinais, bexiga, ureter, uretra. Processos esses que requerem procedimentos cirúrgicos para reposicionamento de vísceras, retirada de corpos estranhos ou cálculos. ${ }^{2}$

Os processos obstrutivos do intestino grosso podem ser causados por compactações, deslocamentos, corpos estranhos, enterólitos ou fecalitos. Os enterólitos são concreções intestinais, mineralizadas, geralmente formadas por um centro que dá início à precipitação de magnésio, amônia e sais de fosfato, também denominada estruvita. ${ }^{7,8} \mathrm{~A}$ idade dos animais acometidos varia de 5 a 10 anos, indicando que os enterólitos podem ter formação lenta. Corrêa et al. ${ }^{10}$ relataram em estudo retrospectivo realizado na Universidade de São Paulo, que a idade média dos animais acometidos por enterolitíase era de 8,87 anos.

Os locais preferenciais de obstrução por enterólitos são o cólon dorsal direito, cólon transverso e cólon menor, ou ainda com menor freqüência a flexura pélvica. ${ }^{5} \mathrm{Em}$ estudo realizado por $\mathrm{Blue}^{7}, 72 \%$ dos pacientes com enterolitíases apresentavam os cálculos obstruindo o cólon transverso. Há também a afirmação de que assim como as obstruções por enterólitos, os processos causados por corpos estranhos geralmente ocorrem no cólon transverso e no cólon menor. ${ }^{11}$

Visou-se com esse trabalho realizar estudo anátomo-topográfico da parede abdominal para abordagem do cólon transverso e estruturas adjacentes, por meio de inspeção direta e identificação in situ dos tecidos e estruturas dissecados. O maior conhecimento da região possibilitará a realização de novos estudos e desenvolvimento de novas técnicas que venham contribuir no tratamento de afecções intestinais nos eqüinos. 


\section{Material e Método}

\section{Peças Anatômicas}

No presente estudo foram utilizados 10 cadáveres de eqüinos de diferentes raças, idades e sexo, provenientes do serviço de Anatomia Patológica da Faculdade de Medicina Veterinária e Zootecnia da Universidade de São Paulo. Os cadáveres foram selecionados dentre aqueles que foram a óbito ou que foram submetidos à eutanásia, e que não sofriam de enfermidades que alterassem a conformação dos órgãos abdominais, assim como sua disposição topográfica. Esses fatores foram avaliados de acordo com o histórico e a procedência dos animais. As peças foram utilizadas a fresco ou após conservação em câmara fria $\left(-3^{\circ} \mathrm{C}\right)$ por até $72 \mathrm{~h}$ em decúbito lateral direito.

\section{Técnica de Dissecção}

Após realizar ampla tricotomia da fossa paralombar esquerda, abrangendo da linha do dorso à linha média abdominal ventral, e da região da escápula à tuberosidade coxal, foi feita a incisão de acordo com a técnica escolhida para cada grupo de peças anatômicas.

O estudo foi dividido em dois grupos de cinco peças anatômicas, objetivando obter o melhor acesso sem que a cavidade torácica fosse exposta. Nas cinco primeiras peças o $16^{\circ}$ espaço intercostal esquerdo foi identificado e nele foi feita uma incisão iniciando na borda do músculo longíssimus dorsi, e terminando na articulação costo-condral. Posteriormente foi dissecada a $16^{\mathrm{a}}$ costela, e com o auxílio de um fio-serra, foi realizada a ressecção da porção visível da $16^{\mathrm{a}}$ costela (Figura 1).

No segundo grupo, foi realizada a incisão sobre a $17^{a}$ costela esquerda, o que facilitou sua dessecação, e a passagem do fioserra. Para a remoção da $17^{\circ}$ costela seguiuse a mesma técnica descrita anteriormente (Figura 1).

Da incisão à entrada na cavidade abdominal, todas as estruturas foram dissecadas, identificadas e documentadas, em ficha individual.

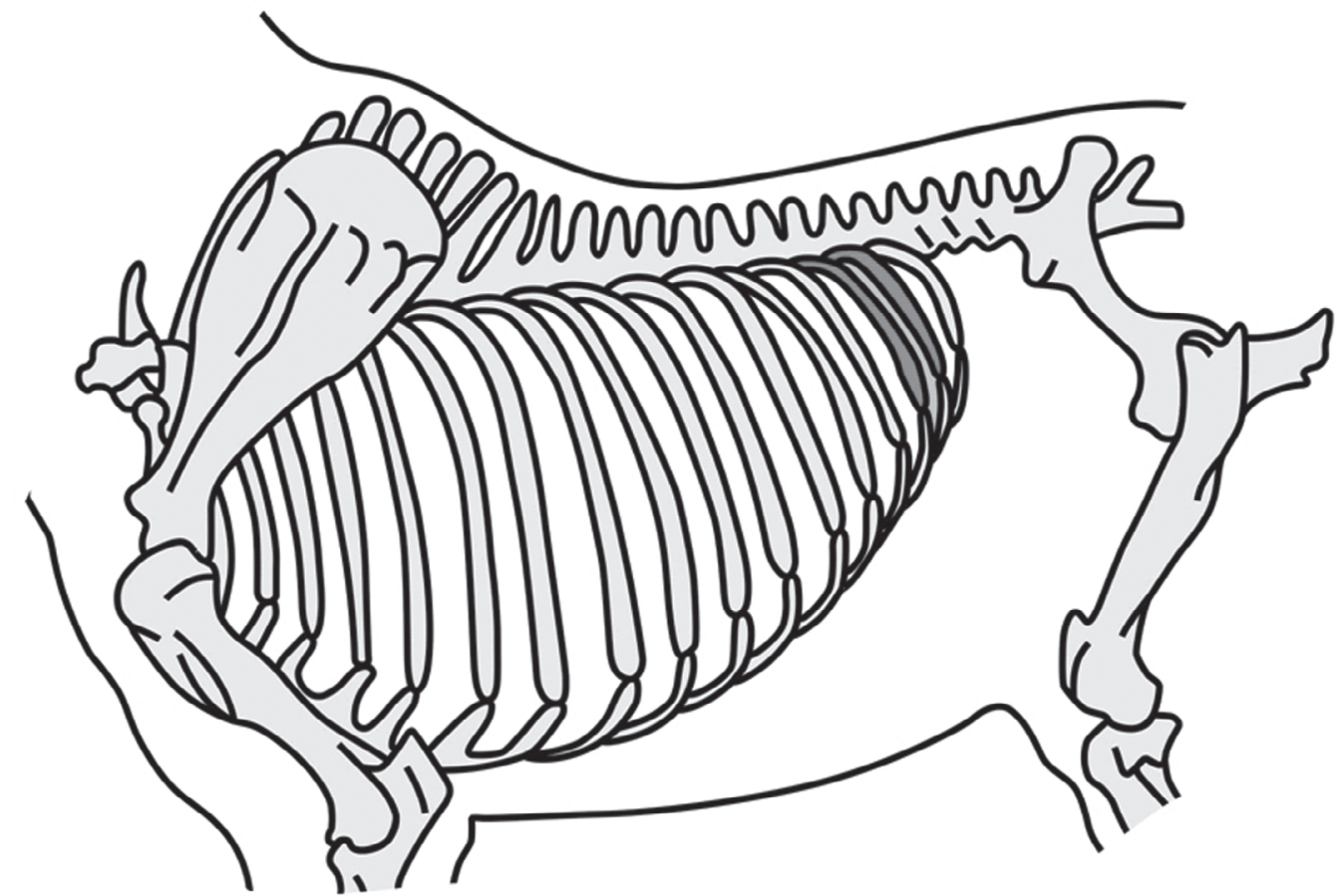

Figura 1 - Esquema mostrando o local da incisão nos grupos 1 e 2: $16^{\circ}$ espaço intercostal esquerdo entre a $16^{\mathrm{a}}$ e $17^{\mathrm{a}}$ costelas verificados em sombreado 


\section{Resultados e Discussão}

Após a incisão de pele, a primeira estrutura identificada foi o músculo cutâneo do tronco e a fáscia superficial intimamente aderidos à derme, ou seja, o panículo carnoso. A próxima estrutura localizada foi o panículo adiposo, um depósito de gordura que pode estar exuberante ou reduzido, dependendo do estado nutricional do animal.

Seguindo em direção ao peritônio, foram identificados os músculos serrátil dorsal caudal em posição mais dorsal, com fibras musculares orientadas no sentido crânio-ventral caudo-dorsal, e o músculo intercostal externo, com os feixes musculares perpendiculares às costelas. $\mathrm{O}$ músculo oblíquo externo do abdômen também foi identificado, orientado transversalmente ao serrátil dorsal caudal, estando em posição mais ventral.

A última estrutura encontrada antes do peritônio foi o músculo intercostal interno, e após sua identificação e incisão, foi feita a incisão do peritônio e entrada na cavidade abdominal.

As primeiras estruturas visualizadas foram o baço e segmentos de intestino delgado (jejuno), que foram afastados para possibilitar a passagem da mão e localização do cólon transverso. Então, para aumentar o acesso a este, e possibilitar sua visualização, procedeu-se a remoção da $16^{\mathrm{a}}$ ou $17^{\mathrm{a}}$, de acordo com o grupo a que pertenceu cada peça anatômica.

A próxima etapa foi a colocação de um afastador auto-estático no acesso realizado, e consecutiva exteriorização das alças do intestino delgado, quando necessária, a fim de estabelecer uma boa visualização do cólon transverso. O cólon transverso foi exteriorizado ao máximo, para permitir a mensuração do comprimento de alça que pôde ser manipulada com facilidade.

Corroborando com as descrições anatômicas feitas por Auer ${ }^{2}$, Dyce, Sack e Wensing ${ }^{3}$, Sisson e Getty ${ }^{1}$, o cólon transverso pode ser acessado pelo flanco esquerdo, visto que em todas as peças anatômicas essa estrutura pode ser visualizada, palpada e parcialmente exteriorizada.

Quanto ao local da incisão, inicialmente realizada no $16^{\circ}$ espaço intercostal, observouse que esse foi eficiente para acessar o cólon transverso. Em todos os casos, mesmo antes da ressecção da costela, o cólon transverso e/ou o início do cólon menor foram identificados. Porém, esse acesso mostrou ser muito cranial, visto que a cavidade torácica foi acessada por toda a extensão da incisão, após a remoção da $16^{a}$ costela (Figura 2). Onde se pode visualizar o pulmão esquerdo.

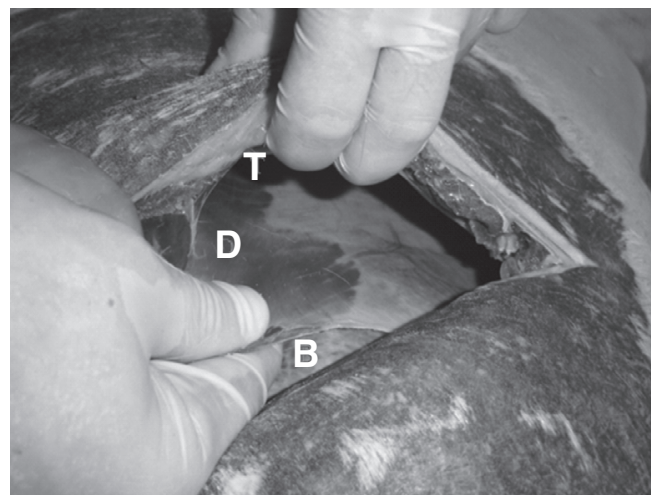

Figura 2 - Imagem digitalizada do acesso pelo $16^{\circ}$ espaço intercostal, evidenciando: D diafragma, B baço, $\mathrm{T}$ cavidade torácica

Outra observação, é que neste acesso pôde-se identificar o nervo intercostal do respectivo espaço, além de tornar necessária a remoção de uma porção do músculo intercostal interno, no $16^{\circ}$ espaço intercostal junto com a respectiva costela. Por esses motivos, optou-se por fazer a incisão sobre a $17^{\mathrm{a}}$ costela, facilitando a dessecação, e procurando evitar a incisão do diafragma, fazendo o acesso caudal com relação ao realizado na $16^{\mathrm{a}}$ costela.

A remoção da $17^{a}$ costela proporcionou maior visualização e melhor manipulação do cólon transverso, e do cólon menor, quando comparadas com a remoção da $16^{a}$ costela, concordando com Sisson e Getty $^{1}$ e Auer ${ }^{2}$, quanto à posição do cólon transverso em relação ao gradil costal. Constatou-se que a ressecção da $17^{\mathrm{a}}$ costela é mais indicada devido à inserção do diafragma e possibilidade de acessar o cólon transverso sem estabelecer comunicação com 
a cavidade torácica.

Desta forma, nas peças 6 e 7, após a remoção de toda a porção visível da costela, o tórax foi penetrado na metade dorsal da incisão. Apesar de ainda não ser o resultado esperado, essa técnica facilitou a realização do procedimento, e melhorou a manipulação e a visualização do cólon transverso, sendo que em ambas as peças a tênia do cólon transverso foi identificada imediatamente após a incisão do peritônio.

Nas três últimas peças, ainda na tentativa de evitar a incisão do diafragma, e da pleura, após dissecar a $17^{\mathrm{a}}$ costela, foi feita uma pequena incisão no $17^{\circ}$ espaço intercostal, na região da articulação costocondral. Então a cavidade abdominal foi acessada, permitindo a palpação da face interna da costela, e identificação do ponto inicial de inserção do diafragma, tornando seguro o prolongamento da incisão. No ponto de inserção do diafragma, a incisão foi interrompida e a porção ventral da costela foi removida.

$\mathrm{Na} 8^{a}$ peça anatômica, foi possível a remoção de um fragmento de costela de somente nove centímetros e a incisão necessitou ser ampliada ventralmente no espaço intercostal, para possibilitar a exteriorização de segmentos de intestino delgado, e melhorar a visualização do cólon transverso. Nas duas últimas peças anatômicas o acesso e a visualização do cólon transverso foram mais eficientes, apesar de a extensão visualizada ser menor (Tabela 1), sendo que na nona peça foram removidos quinze centímetros de costela, estabelecendo um acesso por todo o terço distal da incisão. $\mathrm{Na}$ última peça, o fragmento de costela retirado foi de $22 \mathrm{~cm}$, estabelecendo acesso ao abdômen por toda a extensão da incisão.

O emprego dessa técnica possibilitou o acesso do cólon transverso sem comunicação com a cavidade torácica, porém por meio de uma incisão menor (Figura 3).

Ao analisar as duas diferentes técnicas empregadas para a ressecção da $16^{\mathrm{a}}$ ou $17^{\mathrm{a}}$ costela, notou-se que a incisão sobre a costela, praticada no grupo 2 (grupo no qual a $17^{\mathrm{a}}$ costela foi ressecada), tornou o procedimento

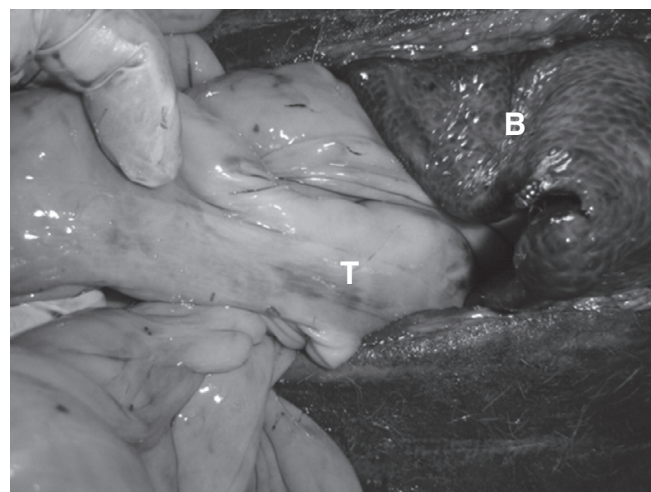

Figura 3 - Imagem digitalizada das estruturas abdominais após ressecção parcial da $17^{\mathrm{a}}$ costela sem invasão da cavidade torácica. T tênia do cólon transverso, B baço

mais fácil de ser realizado. Desta forma, foi desnecessária a realização de uma incisão paralela ao músculo longo do dorso para a dessecação da costela e passagem do fioserra, como ocorreu nos acessos sobre o $16^{\circ}$ espaço intercostal, realizados no grupo 1 (grupo em que se praticou remoção da $16^{\mathrm{a}}$ costela).

A comparação das técnicas dos diferentes grupos foi de extrema importância por identificar o acesso à cavidade torácica, nos animais onde se realizou a ressecção da $16^{\mathrm{a}}$ costela. Este ocorrência é de relevância cirúrgica, por causar aumento direto do trauma cirúrgico, e pelo fato de induzir o pneumotórax unilateral. ${ }^{12}$

Outro importante resultado obtido com o estudo proposto foi o acesso ao cólon menor desde seu início em região distal do cólon transverso, sendo que em todas as peças anatômicas estudadas, pudemos exteriorizar um grande segmento de cólon menor através da incisão realizada no flanco esquerdo (Figura 4).

O conhecimento da anatomia regional do cólon transverso poderá auxiliar em melhorias dos procedimentos cirúrgicos por estes acessos, para a correção de processos obstrutivos do cólon transverso e cólon menor, evitando o uso de técnicas alternativas, como a manipulação intraluminal da área obstruída citada por Mcilwraiht e Turner ${ }^{13}$. 
Tabela 1 - Achados individuais obtidos nas peças anatômicas dissecadas, quanto à costela ressecada, acesso à cavidade torácica, tamanho do fragmento de costela ressecado, estruturas abdominais visualizadas e porção parcialmente exteriorizada do cólon transverso. São Paulo, 2005

\begin{tabular}{|c|c|c|c|c|c|}
\hline $\begin{array}{l}\mathrm{N}^{0} \text { do } \\
\text { animal }\end{array}$ & $\begin{array}{c}\text { Costela } \\
\text { Ressecada }\end{array}$ & $\begin{array}{l}\text { Acesso à } \\
\text { Cavidade } \\
\text { Torácica }\end{array}$ & $\begin{array}{c}\text { Tamanho } \\
\text { do Fragmento } \\
\text { de Costela }\end{array}$ & $\begin{array}{c}\text { Estruturas } \\
\text { Abdominais } \\
\text { Visualizadas* }\end{array}$ & $\begin{array}{c}\text { Porção } \\
\text { Parcialmente } \\
\text { Exteriorizada } \\
\text { do Cólon } \\
\text { Transverso ** }\end{array}$ \\
\hline 1 & $16^{\mathrm{a}}$ & $\begin{array}{l}\text { Em toda } \\
\text { incisão }\end{array}$ & $\begin{array}{c}\text { Toda a porção } \\
\text { visível }\end{array}$ & Baço, ID, CM, CDE & 8 a $10 \mathrm{~cm}$ \\
\hline 2 & $16^{\mathrm{a}}$ & $\begin{array}{l}\text { Em toda } \\
\text { incisão }\end{array}$ & $\begin{array}{c}\text { Toda a porção } \\
\text { visível }\end{array}$ & CM, CT, baço, ID & 10 a $12 \mathrm{~cm}$ \\
\hline 3 & $16^{\mathrm{a}}$ & $\begin{array}{l}\text { Em toda } \\
\text { incisão }\end{array}$ & $\begin{array}{c}\text { Toda a porção } \\
\text { visivel }\end{array}$ & Baço, CM, CT & $7 \mathrm{~cm}$ \\
\hline 4 & $16^{\mathrm{a}}$ & $\begin{array}{l}\text { Em toda } \\
\text { incisão }\end{array}$ & $\begin{array}{c}\text { Toda a porção } \\
\text { visivel }\end{array}$ & Baço, CM, CT & 8 a $10 \mathrm{~cm}$ \\
\hline 5 & $16^{\mathrm{a}}$ & $\begin{array}{l}\text { Em toda } \\
\text { incisão }\end{array}$ & $\begin{array}{c}\text { Toda a porção } \\
\text { visivel }\end{array}$ & ID, baço & $10 \mathrm{~cm}$ \\
\hline 6 & $17^{\mathrm{a}}$ & $\begin{array}{l}\text { Metade } \\
\text { superior }\end{array}$ & $\begin{array}{c}\text { Toda a porção } \\
\text { visivel }\end{array}$ & Baço, CT & $10 \mathrm{~cm}$ \\
\hline 7 & $17^{\mathrm{a}}$ & $\begin{array}{l}\text { Metade } \\
\text { superior }\end{array}$ & $\begin{array}{c}\text { Toda a porção } \\
\text { visivel }\end{array}$ & $\begin{array}{c}\text { Baço, CT, CM, rim } \\
\text { esquerdo }\end{array}$ & $8 \mathrm{~cm}$ \\
\hline 8 & $17^{\mathrm{a}}$ & Não & $9 \mathrm{~cm}$ & $\begin{array}{c}\mathrm{Baço}, \mathrm{CT}, \mathrm{CM}, \mathrm{ID}, \\
\text { ceco }\end{array}$ & $7 \mathrm{~cm}$ \\
\hline 9 & $17^{\mathrm{a}}$ & Não & $15 \mathrm{~cm}$ & Baço, CM, CT & $6 \mathrm{~cm}$ \\
\hline 10 & $17^{a}$ & Não & $22 \mathrm{~cm}$ & ID, CM, baço, CT & 6 a $7 \mathrm{~cm}$ \\
\hline
\end{tabular}

ID intestino delgado (jejuno), CM cólon menor, CDE cólon dorsal direito, CT cólon transverso,

* Estruturas identificadas imediatamente após a incisão do peritônio.

** Valor aproximado em centímetros.

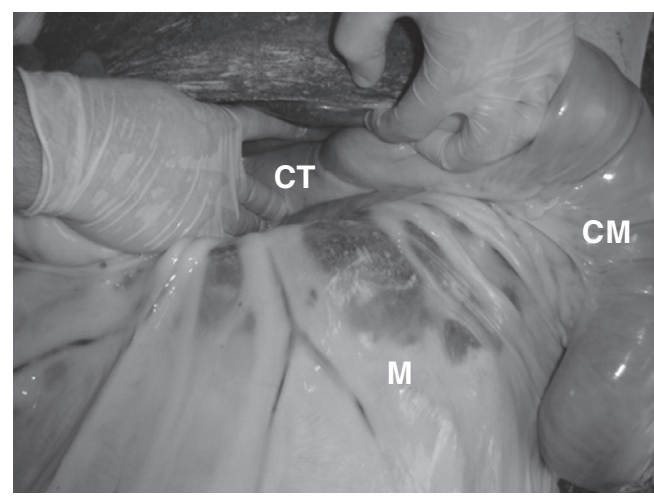

Figura 4 - Imagem digitalizada do cólon transverso visualizado através da incisão na $17^{a}$ costela, e cólon menor exteriorizado: CM cólon menor, $\mathbf{M}$ mesecólon, $\mathbf{C T}$ cólon transverso

\section{Conclusões}

Após a realização do estudo anátomo-cirúrgico em dez cadáveres, concluiu-se que a porção final do cólon transverso e inicial cólon menor podem ser eficientemente acessados pela fossa paralombar esquerda, assim como o início do cólon menor. Concluiu-se também que a melhor técnica para esse procedimento foi a ressecção da $17^{\circ}$ costela, que permitiu evitar a invasão da cavidade torácica.

Agradecimentos: Trabalho realizado com apoio do CNPq/PIBIC

\section{Anatomic and surgical study of the equine transverse colon from left paralombar aprouch}

\section{Abstract}

The transverse colon is a constriction of the bowel lumen, which can be submitted to obstructive process. The knowledge enlargement about this structure and the adjacent ones has a great surgical
Key word:

Transverse colon. Enterolith. Equine. Colic.

Acute abdomen 
importance. For such study, ten anatomic pieces, from equines corpses of different breed, age and sex, were used and divided in two groups. In the first group an incision was made in the left 16 intercostal space and farther resection of the 16 rib. In the second group an incision was made over the $17 \mathrm{rib}$, before its ressection. All the identified structures were registered into individual files, such as the extension of the exteriorized portion. In all of the studied pieces, the transverse colon was entirely visualized and partially exteriorized. However, we had better handling and exteriorization in the second group, as well as we noticed its technique was of easier execution. In accordance with the results, through this work is possible to conclude that the transverse colon can be approached by the left flank, and that the removal of the 17 rib provides a better access to the transverse colon.

\section{Referências}

1 SISSON, S.; GETTY, R. Anatomia dos animais domésticos. $5^{\mathrm{a}}$ ed. Rio de Janeiro: Guanabara Koogan, 1981. 2000 p.

2 AUER, J. A. Equine surgery. Philadelphia: Saunders, 1992. $1214 \mathrm{p}$

3 DYCE, K. M.; SACK, W. O.; WENSING, C. J. G. Tratado de anatomia veterinária. Rio de Janeiro: Elsevier, 2004. 813 p.

4 SNYDER, J. R.; SPIER, S. J.; SMITH, B. P. Diseases of the large intestine associated with acute abdominal pain. In: SMITH, B. P. Large animal internal medicine. St. Louis: Mosby-Year Book, 1990. p. 694-703.

5 KELLER, S. D.; HORNEY, F. D. Diseases of the equine small colon. Compendium Continuing Education for the Practicing Veterinarian, v. 7, n. 2, p. 122-133, 1985.

6 MURRAY, R. C.; GREEN, E. M.; CONSTANTINESCU, G. M. Equine enterolithiasis. Compendium Continuing Education for the Practicing Veterinarian, v. 14, n. 8 , p. 1104-1112, 1992

7 BLUE, M. G. Enteroliths in horses - a retrospective study of 30 cases. Equine Veterinary Journal, v. 11, n. 2, p. 76-84, 1979.

8 BLUE, M. G.; WITTKOPP, R. W. Clinical and structural features of equine enteroliths. Journal of American Veterinary Medicine Association, v. 179, n. 1, p. 79-82, 1981.

9 LLOYD, K. et al. Enteroliths in horses. Cornell Veterinary, v. 77, p. 172-186, 1987.

10 CORRÊA, R. R. et al. Estudo retrospectivo dos casos de enterolitíases e corpo estranho em intestino grosso de eqüinos, no período de janeiro de 1993 a janeiro de 2003. Brazilian Journal of Veterinary Research and Animal Science, v. 43, n. 2, p. 242-249, 2006.

11 MEAGHER, D. M. Obstructive disease in the large intestine of the horse: Diagnosis and treatment. Proc. Am. Assoc. Equine Pract., n. 18.p. 269-279, 1972.

12 BACCARIN, R. Y. A. et al. Tórax agudo em eqüinos. Revista de Educação Continuada CRMV-SP, v. 5, n. 1, p. 59-72, 2002.

13 MCILWRAITH, C. W.; TURNER, A. S. Equine surgery advanced techniques. Philadelphia: Lea \& Febiger, 1987. 391 p. 